\title{
Colour Terms in Advertisements
}

\author{
Kristine Harutyunyan \\ Yerevan State University
}

\begin{abstract}
The present article focuses on the peculiarities of the usage of colour terminology in advertisements. We live in a colourful world and there are great many colour words to describe it. We also live in a world where advertisement has become an accompanying phenomenon of our everyday life. It is obvious that the language of advertising has its specific features and it seems worth trying to reveal the role and the meaning of the colours used in advertisements. Colour terms are known to be linguistic universals which have certain associations attached to each of them. We may suppose that the colours that are mostly used in the advertisements are the basic colour terms. The spheres where we expect to find wider usage of colour terms should be the ones connected with fashion industry.
\end{abstract}

Key words: colour terms, advertisements, hue, lightness, saturation, symbolism.

\section{Introduction}

The study of colour terms has a very long history. Nearly 2,500 years ago, colour was systematically studied for the first time as a basic cognitive domain. As might be expected, different research traditions employ different methods: work with colour arrays (naming, mapping, identifying focal point) is a traditional anthropological method; response time, consistency and consensus of naming, and elicited lists are often used by psychologists; frequency in texts, morphology and word length have been part of the linguistic approach. Our aim is to study the colour terms in advertisements. We should note that advertisement is characterized mainly by the following aspects: concision, clarity, frequent use of comparative and superlative constructions, neologism, repetition, non-sophistication, and application of rhetorical devices. Since the main purpose of advertisement is to send out a message to public or consumers to promote the sale of a product or service, to influence public opinion, to gain political support, to advance a particular cause, or to elicit some other response desired by the advertiser, it is imperative that they be clearly and flexibly rendered particularly if it is intended for foreigners. Purposeful use of comparative and superlative constructions, neologisms, and repetitions shall maintain and even strengthen the appealing effect of the original advertisement.

\section{Physical Perception of Colour and Colour Symbolism}

Most speakers of a language are aware of different qualities or dimensions intrinsic to the concept of colour. First, there is colour itself - we can distinguish red from 
yellow, for instance. But the fact is that we often qualify colour terms to account for the other dimensions. Thus, we can talk about "a dark red" but also "a dull red"; "a light red" but also "a bright red". These phrases reflect a three-way distinction or distinct attributes of the colour terms. They are as follows: Hue, Lightness and Saturation.

Although it is not uncontroversial to reduce colour to these three dimensions, one has to admit that the colour terms of English can readily be analysed in this way. Even so, it is clear, and this will be demonstrated below, that other dimensions can be evoked through context in English. It is important to realize how these dimensions are coded linguistically, and, thus, address the question of appropriate terminology.

Consider first the term hue, normally associated with color. A.H. Munsell defines hue as follows: "It is that quality by which we distinguish one colour family from another, as red from yellow, green from blue or purple. It is specifically and technically that distinctive quality of colouring in an object or on a surface; the respect in which red, yellow, green, blue, and purple differ from one another; that quality in which colours of equal luminosity and chroma may differ" (Munsell 1961:15).

Since hue corresponds to what we normally associate with colour, modification of 'a colour' in respect to hue is usually achieved with the help of another colour term, often a derived form, e.g. reddish purple, or yellowish green.

Lightness - the second dimension of colour is the "quality by which we distinguish a light colour from a dark one" (Munsell 1961:15). There is a wealth of terms currently used to refer to this dimension. Frequently used terms are value (Munsell 1961), lightness, brightness (Berlin and Kay 1969) and tone. Everyday language usually emphasizes lightness by the terms dark and pale.

The third dimension of color is that of saturation or chroma. It is the quality of a color by which a strong colour is distinguished from a weak one; the degree of departure of a colour sensation from that of white or grey; the intensity of a distinctive Hue; colour intensity. (Munsell 1961:16) As the term saturation is rather uncontroversial and usually preferred, it is used in this study. Dull or greyish and vivid or bright are used in every-day speech to refer to low and high saturation, respectively. The figure below shows Munsell's colour system:

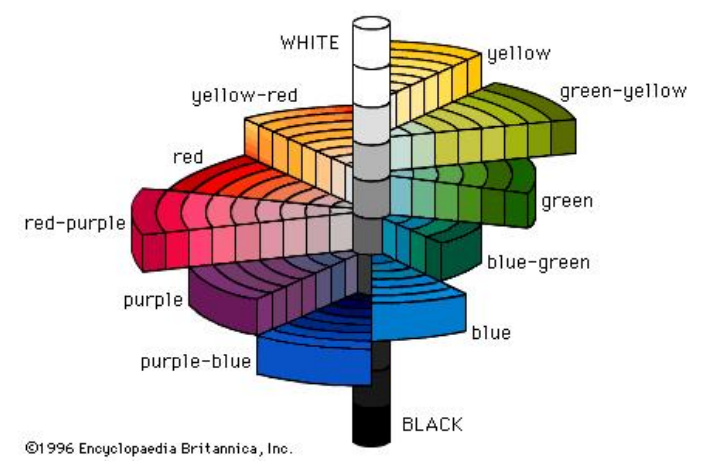


The use of colour terms in advertising texts will indubitably make the latter more effective and influential. Colour terms can influence not only visually. Their influence can also be conditioned by the consumer's perception regarding the quality or just the goods themselves.

Colour terms used in advertising texts can symbolize a number of issues or phenomena. Let us begin with the colour red. Thus, for example, red is the colour of fire and blood, it is associated with energy, war, danger, strength, power, determination as well as passion, desire, and love.

Red is an emotionally intense colour. It enhances human metabolism, increases respiration rate, and raises blood pressure. It has very high visibility, which is why stop signs, stoplights, and fire equipment are usually painted red. In heraldry, red is used to indicate courage. It is a colour found in many national flags.

Red brings text and images to the foreground. It is used as an accent colour to stimulate people to make quick decisions; it is a perfect colour for 'Buy Now' or 'Click Here' buttons on Internet banners and websites. In advertising, red is often used to evoke erotic feelings (red lips, red nails, red-light districts, 'Lady in Red', etc.). Red is widely used to indicate danger (high voltage signs, traffic lights). This colour is also commonly associated with energy, it is used for promoting energy drinks, games, cars, items related to sports and high physical activity:

Maybelline colour sensational lip color in red revival

This lipstick leaves behind a finish that's as shiny as red-hot patent leather pumps. Maybelline Color Sensational Lip Colour in Red Revivalfeel as if you are in red.

(http://www.cosmopolitan.com/style-beauty/beauty/advise/g3384/best-redlipstick $/ \times$ slide $=6$ )

\section{Nutrisse Mousse Medium Ultra Intense Red}

Looking for an easy foam application but not willing to sacrifice on results $\times$ NEW Garnier Nutrisse Mousse: the 1st foam to NOURISH while it colours. Our zero compromise formula offers multi-dimensional color results, 100\% grey coverage, and an easy to use, no mess application. Enriched with avocado, olive, and shea oils, its rich conditioner leaves hair silky, soft and healthy-looking. Nutrisse Mousse Medium Ultra Intense Redmake your hair look brighter and red as a wild rose.

( $<$ http://www.garnier.ca/en-ca/hair-color/beauty/garnier/nutrissemousse/medium-ultra-intense-red $>$ )

Red, because "it is the colour of life, of blood", as Gabrielle Chanel said. Red because it permits, when used as the lining of a purse, a quick find of what one is looking for. Red, because, worn on the lips, it became 
Gabrielle's signature and her declaration of good spirit. "If you're sad, add more lipstick and attack. Men hate women who weep", Mademoiselle asserted.

(<Colors of Chanel: < http://inside.chanel.com/ru/colors-of-chanel/video $>$ )

In the examples adduced above the colour term red is used in its connotative meaning and symbolizes passion and beauty. In the first example red is used as a metaphor and symbolizes passion, while in the second example where it is used in a simile, red is compared with wild rose and symbolizes beauty and strength, thus being used as a simile. Finally in the third example we again deal with the metaphoric use of the word red and it symbolizes passion and beauty.

White is associated with light, goodness, innocence, purity, and virginity. It is considered to be the colour of perfection. As opposed to black, white usually has a positive connotation. White can represent a successful beginning. In heraldry, white depicts faith and purity. In advertising, white is associated with coolness and cleanliness because it is the colour of snow. You can use white to suggest simplicity in high-tech products. White is an appropriate colour for charitable organizations; angels are usually imagined wearing white clothes. White is associated with hospitals, doctors, and sterility, so you can use white to suggest safety when promoting medical products. It is often associated with low weight, low-fat food, and dairy products as well.

People in Christian countries believe that Jesus and his angels wear white dress, so the colour white is the holiest colour in Christianity. "White spirit" refers to a person who has a pure heart and always does goods to others. "A white man" means a person who has virtues. In most of the western cultures weddings taking place in the church are called "white wedding", because the brides are dressed in white, white is applied to describe the quality or state of being pure.

White also bears a meaning of innocence. In fact a man who is honest or innocent can be expressed as "white hands". In English, "a white elephant" means possession that is useless and often expensive to maintain. White here stands for useless. The examples of the advertisements with white are:

“Heeeey, heeey, Suzy Q, your teeth look whiter like winter, like snow like new new new!!!”

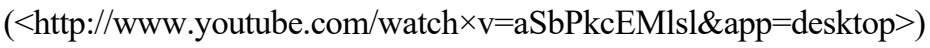

A red sock or pair of pants accidentally mixed in with your whites can turn your whole wash pink. Ariel with Actilif Color helps lock in colors and prevent color running from darker garments onto lighter ones. Keep your clothes as white as the snowfalls with Ariel Actlift Colour.

( $<$ http://www.ariel.co.uk/LaundryTips/ArielTips/Undo.com your laundry.aspx $>$ ) 
In both sentences the colour term white is used in a simile and symbolizes purity, coolness and cleanliness as it is compared with snow.

White, because at the beginning there was white. Because it captures the light, illuminates the face and enhance beauty. Because it's the colour of

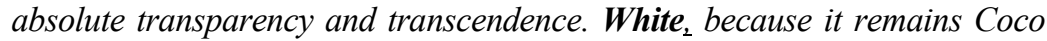
the cornettes of the nuns from her childhood and the communion dress given to her by her father.

(Colors of Chanel http://inside.chanel.com/ru/colors-of-chanel/video)

In this example the colour term white is used in its symbolic meaning standing for purity and transparency.

The colour terms white and black often symbolize contrasting meanings. Black is the absorption of all colours and the absence of light. Black hides, while white brings to light. What black covers, white uncovers.

In the western world black is associated with power, elegance, formality. In Christianity it is connected with death, evil, and mystery. It is a mysterious colour associated with fear and the unknown (black holes) and usually has a negative connotation (blacklist, black humor, black death). Black denotes strength and authority; it is considered to be a very formal, elegant, and prestigious color (black tie, black Mercedes). Authoritative and powerful, the colour black can evoke strong emotions and too much black can be overwhelming. In heraldry, black is the symbol of grief. This colour gives the feeling of perspective and depth, but a black background diminishes readability.

Black often represents the emotions and actions of rebellion in teenagers and youth.

The colour black can represent both the positive and the negative. In media we usually see the "white guy" opposed to the "black guy", "white" being "good" and "black' being "bad". In more recent times, the good guy is shown in black to create mystery around the character's identity. Thus, "white man" is not just white in skin but has the meaning of "Yank". Moreover it acquired the meaning of "an educated, wellbred, polite person". On the other hand "black man" often symbolizes "the evil and demons". But we can see black in advertisements as well:

“Gorgeous, absolutely hot in black...With Perwoll black magic black stays black like new!”

(<https://www.youtube.com/watch $\times \mathrm{v}=5$ hPMRODfG68 $>$ )

Black opium - free, unique, femininity that is chic, sensual and brazen. Black opium-you'll be in black.

$(<$ https://www.youtube.com $/$ watch $\times \mathrm{v}=\mathrm{dZJL}>)$ 
Black, because it accentuates the essential and recalls the monastic rigor of the uniforms at the Aubazine orphanage. Because for Gabrielle Chanel, "it reveals a woman's radiance." Thanks to Chanel, black evolved from the garments of servants and those in mourning to become, since 1926, in the colour of elegance, epitomized by the little black dress. "I imposed black and it reigns still because black trumps all," said Mademoiselle.

(Colors of Chanel: <http://inside.chanel.com/ru/colors-of-chanel/video $>$ )

In the examples the colour term black is a metaphor, (black magic). In the last example it symbolizes elegance, while in the second sentence it stands for mystery.

The colour term green symbolizes youth, hope and happiness for many nationalities.

Green is the colour of nature. It symbolizes growth, harmony, freshness, and fertility. It has a strong emotional association with safety. Green, as the color of plants and grass, is the color of nature and all that is associated with health and growth. However, it is also used to represent more negative traits such as envy and inexperience.

Sometimes green denotes lack of experience; for example, a 'greenhorn' is a novice. In heraldry green indicates growth and hope.

Green, as opposed to red, means safety; it is the color of free passage in road traffic. It is also used to indicate safety when advertising drugs and medical products. Besides, green is associated with gambling games as well.

Moreover, being directly related to nature, it can also be used to promote 'green' products. Dull, darker green is commonly associated with money, the financial world, banking, and Wall Street.

It is the most restful colour for the human eye, hence it can improve vision. Green has a great healing power:

"100\% dry, your hair is rough, broken. Now there is new Fructis oil repair. It's green energy for dry hair, the avocado oil nurish and trnasform dry hair to smoother shinier hair. Put green energy into your hair with new Fructis oil repair."

$(<$ http://www.youtube.com/watch $\times \mathrm{v}=$ ZtPddsZp14 $>$ )

"Green as tranquil and exotic, modern and ancient, green as soothing, green as tenacious. Is there anything quite like green $\times$ Tetly green tea."

$$
(<\text { http://www.youtube.com/watch } \times \text { v }=\text { J8Elk5B8GqA }>)
$$

In the first example green is used as a metaphor in the phrase "green energy", thus symbolizing growth and freshness. In the second example the associations of green with 
nature, (mainly with a plant), give us grounds to believe that it symbolizes harmony, calmness and freshness.

Yellow is the colour of sunshine. It is associated with joy, happiness, intellect, and energy.

Yellow produces a warming effect, arouses cheerfulness, stimulates mental activity, and generates muscle energy. Yellow is often associated with food. Yellow is seen before other colours when placed against black; this combination is often used to issue a warning.

The colour term yellow evokes pleasant, cheerful feelings and is used to promote children's products and items related to leisure. Men usually perceive yellow as a very 'lighthearted', 'childish' colour. Yellow is an unstable and spontaneous color, so one should avoid using yellow if he/she wants to suggest stability and safety. Light yellow tends to disappear into white, so it usually needs a dark color to highlight it.

However, besides its positive meaning, such as indicating honor and loyalty, the term yellow can have a negative meaning as well. In the English language the color term yellow is closely connected with cowardice. Yellow is also closely connected with misconduct and trouble, it heats the imagination and after all it greatly influences the psychology.

Clothing and objects that are yellow in colour still resemble a higher social status. Although each dynasty designated each official rank with their own colour, yellow is reserved for the emperor himself. The yellow colour and its shades are also the main colour of Buddhism; thus it represents being free from worldly cares. While in European countries, as well as in Russia and in Armenia it stands for something sensational:

Be found, wherever your customers are looking. Whether they're looking through the trusty book or searching online, we'll help make it easy for your business to be found. Our advertising solutions feature a broad range of options to suit your unique needs. Knowledge is better shared with us. Find yourself in yellow pages!

(<http://www.yellowadvertising.com.au $>$ )

Here the term yellow is used in the set phrase yellow pages and in European countries it stands for sensation. Thus, in this example it can also be associated with something sensational.

Blue is the most universally favored colour of all and therefore the safest to use. Blue indicates confidence, reliability and responsibility.

Physiologically, blue is calming, reducing tension and fear. Being a cool colour it creates a sensation of space. Blue adds strength and unity, and is therapeutic to the mind and body. It brings harmony to the spoken word. Too much blue can encourage boredom, 
manipulation or a rigid outlook. This is a color that seeks peace and tranquility above everything else, promoting both physical and mental relaxation. It reduces stress, creating a sense of calmness, relaxation and order - we certainly feel a sense of calm if we lie on our backs and look into a bright blue cloudless sky. It slows the metabolism. The paler the blue the more freedom we feel.

Blue is the colour of the spirit, devotion and religious study. It enhances contemplation and prayer. It is a natural colour for water and the sky, but is rarely found in fruits and vegetables. Today, blue is embraced as the colour of heaven and authority, denim jeans and corporate logos. It is cold, wet, and slow as compared to red's warmth, fire, and intensity.

In the English language blue can be associated with sorrow and sadness. But in many countries blue symbolizes eternity. In Christianity it is connected with mystery, while for romantic people it is connected with the colour of the dream and longing. Blue bird is a symbol of success. The colour blue can also symbolize continuity, and in heraldry it symbolizes kindness, sincerity and loyalty:

Blue as a sea, blue as a sky, feel the freshness and purity! Light Blue Summer by Dolce \& Gabbana.

$$
\text { (<http://www.youtube.com/watch } \times \text { v }=\text { zLrUJY4D5Bc }>\text { ) }
$$

In the above mentioned example one can clearly see that the colour term blue is compared to the sea and the sky, thus symbolizing purity and freshness.

The colour pink represents compassion, nurturing and love. It relates to unconditional love and understanding, and the giving and receiving of nurturing. It is the passion and power of red softened with the purity, openness and completeness of white. The deeper the pink, the more passion and energy it exhibits.

Pink is feminine and romantic, affectionate and intimate, thoughtful and caring. It tones down the physical passion of red replacing it with a gentle loving energy. Pink is intuitive and insightful, showing tenderness and kindness with its empathy and sensitivity. In colour psychology, pink is a sign of hope. It is a positive colour inspiring warm and comforting feelings, a sense that everything will be okay. Pink calms and reassures our emotional energies, alleviating feelings of anger, aggression, resentment, abandonment and neglect.

Pink is a non-threatening color seeking appreciation, respect and admiration. It doesn't like to be taken for granted and just loves to hear the words 'thank you'. Pink can signify good health (in the pink), and success (everything's rosy).

The colour pink represents the sweetness and innocence of the child in all of us. It is the colour of uncomplicated emotions, inexperience and naiveté.

Yet pink can represent a lack of will power, a lack of self-reliance and a lack of selfworth. It can indicate an overly emotional and overly cautious nature. 
Combining pink with other darker colors such as dark blue, dark green, black or gray, adds strength and sophistication to pink:

Feel the power of rose just washing your dress with Perwoll magic color pink and you will be in pink!

( $<$ https://www.youtube.com/watch $\times \mathrm{v}=\mathrm{YUCKVrrXwY0>}$ $<$ http://www.perwoll.de/sortiment/perwoll-wolle-und-feines.html $>$ )

In the given example the color term pink can symbolize a light passion, tenderness and sensitivity. As compared with rose it can also be associated with beauty

Brown is a serious, down-to-earth colour signifying stability, structure and support. It is a colour of physical comfort, simplicity and quality. From a negative perspective it can also give the impression of cheapness and stinginess in certain circumstances. Brown is friendly and approachable. It is loyal, trustworthy and dependable in a practical and realistic way.

In colour psychology, brown is honest, genuine and sincere. It relates to the hardworking, the industrious and reliable, with both feet planted firmly on the ground. It is sensual, sensitive and warm, engulfing one in a feeling of calmness and comfort. It is a practical and sensible color which implies common sense. The colour brown is associated with wholesome, natural and organic produce and anything related to the great outdoors, agriculture and farming.

Some browns can show a degree of sophistication or elegance, depending on other colours associated with the brown. For example, brown with a soft white or ivory can appear stylish and classy, although more casual than black with soft white or ivory.

Brown is a colour of structure, although by no means does it encourage perfectionism - rather it encourages orderliness and organization. Brown also gives reassurance. It is solid with strength and maturity. It prefers to function in its own safe little world - it is not carefree and spontaneous and doesn't like surprises. It can be considered dull, boring and unexciting by many. In fact it is one of the least preferred colors in the western world, along with orange and yellow.

Brown is a predominant color on the planet, along with green. Brown is comforting and stabilizing, while green is balancing and rejuvenating.

The psychological meaning of the color brown can vary slightly depending on the colors which are mixed together to create the brown. Brown can be a combination of black, yellow, orange, red, gray, green, blue, pink and purple, and each of the colors in it will add a variation to the meaning:

Only a chocolate is pure, brown as silk, and makes you savor, sigh, melt. Dove, pure brown silk chocolate!

( $<$ http://www.youtube.com/watch $\times \mathrm{v}=$ SwPwQ4S4op8 $>$ ) 
Compared with silk and used to describe chocolate, the colour term brown here is associated with calmness and sensitivity.

Orange radiates warmth and happiness, combining physical energy and stimulation of red with the cheerfulness of yellow.

The color psychology of orange is optimistic and uplifting, rejuvenating our spirit. Orange brings spontaneity and a positive outlook on. With its enthusiasm for life, orange relates to adventure and risk-taking, inspiring physical confidence, competition and independence.

Orange combines the energy of red and the happiness of yellow. It is associated with joy, sunshine, and the tropics. Orange represents enthusiasm, fascination, happiness, creativity, determination, attraction, success, encouragement, and stimulation.

To the human eye, orange is a very hot colour, so it gives the sensation of heat. Nevertheless, orange is not as aggressive as red. It is highly accepted among young people. As a citrus colour, orange is associated with healthy food and stimulates appetite. It is the colour of autumn and harvest. In heraldry, orange is symbolic of strength and endurance.

Orange has very high visibility, so you can use it to catch attention and highlight the most important elements of your design. It is very effective for promoting food products and toys. Dark orange can mean deceit and distrust. Red-orange corresponds to desire, sexual passion, pleasure, domination, aggression, and thirst for action:

New! Garnier hair oil for colour treated hair. This oil for colored hair with custom-blended Morgina \& Sweet Orange oil, illuminates and helps protect color treated hair...Gentle shine...no more tropes because we're worth it too...Garnier hair oil for color treated hair...put on the orange oil and feel the energy.

( $<$ http://garnierusa.com/products/haircare/marvelousoils/treatment/marvelous-oil-color-illuminate.aspx $>$ )

Here orange symbolizes energy, vitality, cheer, excitement, adventure, warmth, and good health.

All the presented examples come to prove that we may come across different colour terms in different advertisements. The symbolic meanings of colours that are attached to each of them are reflected in their usage in the texts of advertisements.

\section{Conclusion}

Thus, we can conclude that colour terms are used in different advertisements and they may have different effect on people. Despite the fact that the language of advertising has certain peculiarities, colour terms prove to retain their universal 
symbolic meanings in the analyzed examples. As expected, advertisements with colour terms mostly belong to spheres connected with fashion and beauty. The so-called basic colour terms are used more frequently in advertisements. It can also be concluded that one may judge for himself/ herself whether the use of the colours will have an influence on him/ her while making decision of buying this or that product. But in all cases colours were, are and will be powerful in all spheres of our life.

\section{References:}

1. Berlin, B.; Kay, P. (1969) Basic Color Terms: Their University and Evolution. Berkeley: University of California Press.

2. Brown, R.; Lenneberg, E.A. (1954) Study in Language and Cognition. Journal of Abnormal Psychology, 49(3).

3. Dedrick, D. (1998) Color Names and Whorf's Hypothesis in Naming the Rainbow: Color Language, Color Science, and Culture. Dordrecht: Kluwer Academic Publishers, 10-24.

4. Kay, P.; Regier T. (2009) Language, Thought and Color: Recent Developments. Trends in Cognitive Sciences, 10(2).

5. Leech, G.N. (1966) English in Advertising. London: Longman.

6. Munsell, A.H. (1961) A Pigment Color System and Notation. University of Illinois Press.

\section{Sources of Data:}

1. <http:/garnierusa.com/products/haircare/marvelous-oils/treatment/marvelous-oilcolor-illuminate.aspx $>$

2. $<$ http://www.youtube.com/watch $\times \mathrm{v}=\mathrm{SwPwQ} 4 \mathrm{~S} 4 \mathrm{op} 8>$ $<$ https://www.youtube.com/watch $\times \mathrm{v}=\mathrm{YUCKVrrXwY0>}$

4. $<$ http://www.perwoll.de/sortiment/perwoll-wolle-und-feines.html $>$

5. $<\mathrm{http}: / /$ www.youtube.com/watch $\times \mathrm{v}=\mathrm{zLrUJY} 4 \mathrm{D} 5 \mathrm{Bc}>$

6. $<$ http://www.yellowadvertising.com.au $>$

7. $<$ http://www.youtube.com/watch $\times$ v $=$ ZtPddsZp14>

8. $<\mathrm{http}: / /$ www.youtube.com/watch $\times \mathrm{v}=\mathrm{J} 8 \mathrm{E}$ Elk5B8GqA $>$

9. <http://inside.chanel.com/ru/colors-of-chanel/video > $<$ https://www.youtube.com/watch $\times$ v $=$ dZJLboWaBCQ $>$ $<$ https://www.youtube.com/watch $\times \mathrm{v}=5$ hPMRODfG68 $>$

12. <http://www.ariel.co.uk/LaundryTips/ArielTips/Undo.com your laundry.aspx> 
13. $<$ http://www.youtube.com/watch $\times$ v $=$ aSbPkcEMlsl\&app=desktop $>$

14. $<$ http://www.garnier.ca/en-ca/hair-color/beauty/garnier/nutrisse-mousse/mediumultra-intense-red $>$

\section{QnıGuugnıGitinn qnumqnGitinnı}

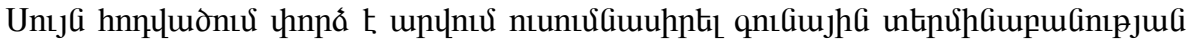

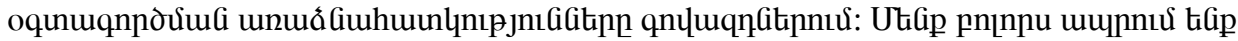

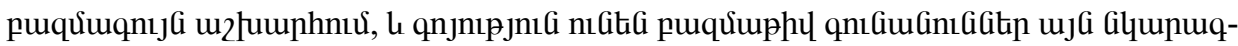

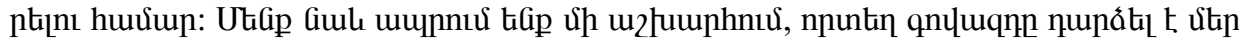

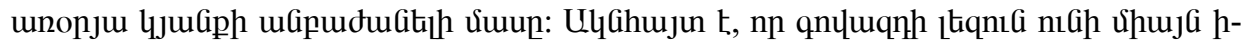

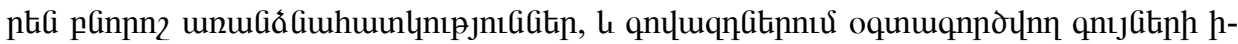

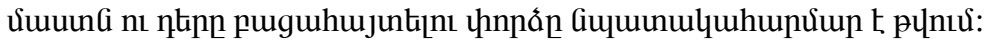

\section{Цветовые термины в рекламе}

Данная статья является попыткой изучения особенностей употребления цветовой терминологии в рекламе. Мы все живем в цветовом мире, и существует множество цветообозначений для его описания. Мы также живем в мире, в котором реклама стала неотьемлемой частью нашей повседневной жизни. Очевидно, то язык рекламы отличается присущими лишь ему особенностями, и попытка выявления смысла и роли цветообозначений употребляемых в рекламе, представляется целесообразной. 